Barbara Pihler

Universidad de Ljubljana

\title{
PARADIGMAS VERBALES EN EL DISCURSO LÍRICO DE MACHADO, JIMÉNEZ Y ALEIXANDRE: EL CRITERIO DE LA ACTUALIDAD
}

Palabras clave: verbo, temporalización, formas actualizadoras e inactualizadoras, discurso lírico

\section{Introducción}

\author{
«Tiempo sin huellas, \\ dame el secreto con que invade \\ cada día tu espíritu a tu cuerpo.» \\ J. R. Jiménez (1967)
}

Desde Aristóteles: «Rema de esti to prossemainon hronon...» ${ }^{1}$ hasta la actualidad se ha mantenido la comprensión del verbo como una 'palabra temporal', como «la más perfecta imagen, el más natural testigo y la primera consciencia del tiempo» (Criado de Val, 1992). En este artículo, sin embargo, partimos de la concepción más amplia: el verbo es un elemento constitutivo primordial tanto en la estructuración sintáctica y la constitución del significado oracional y textual como también, y sobre todo, en la constitución del sentido comunicativo del enunciado (Wotjak, 1990). Sin verbo no hay comunicación eficaz a largo plazo, o bien, los efectos que provoca su ausencia son fuertemente connotativos.

El primordial contenido temporal del verbo ${ }^{2}$ hace que éste sea el punto de partida principal de cualquier investigación e interpretación lingüística de la temporalidad textual. Tradicionalmente se diferencia entre los usos básicos o prototípicos (que es el valor semántico del verbo que puede distinguirse con independencia del contexto) y los usos secundarios, excepcionales o dislocados teniendo en cuenta los contextos específicos. Por ejemplo, el uso prototípico del presente (canto) consistiría en la coincidencia entre el tiempo del habla (H), punto de referencia (R) y tiempo del evento (E): leo un libro (H,R,E), mientras que los usos secundarios del mismo paradigma ${ }^{3}$ serían ayer leo un libro, cuando

1 Ej. Aristoteles, Peri hermeneias, III,1. El ejemplo está citado en Binick, R. (1991).

2 El contenido temporal se puede expresar también con otras categorías lingüísticas, por ejemplo, en el sustantivo bisabuelo el prefijo bis- ubica indudablemente a esta persona en el intervalo anterior a mi nacimiento en la línea temporal.

3 Preferimos emplear el término de paradigma verbal para evitar las ambigüedades entre los conceptos del tiempo como la cuarta dimensión y el tiempo verbal como la entidad lingüística. El concepto de paradigma verbal resulta más preciso y a la vez más amplio del significado clásico del tense; es un esquema organizado y ya de por sí solo representa la incongruencia entre la realidad extra-lingüística y su percepción y expresión por parte de los hablantes. 
me llama por teléfono; mañana te llamo, etc.; es decir, cuando el tiempo del evento es anterior al tiempo del habla y/o al revés.

Como la lengua es un organismo vivo hay que analizarla siempre en el proceso de significación, que es la comunicación en el sentido más amplio de la palabra. El marco teórico para analizar el uso de cualquier enunciado debe ser así la pragmática, o bien, la lingüística pragmática (Fuentes Rodríguez, 2000) ya que es en el uso de la lengua donde se pueden manifestar todas las posibilidades del sistema. De ahí que la alta frecuencia, además, de los usos llamados secundarios o dislocados de la mayoría de los paradigmas verbales españoles (los usos más debatidos son sin duda cantaba y cantara ${ }^{4}$ ) y la persistencia de ellos entre los hablantes, obligue a reflexionar sobre otras posibilidades de interpretación. Partimos del camino que se inició con los empleos polifónicos de O. Ducrot (1984), los valores pragmáticos y usos citativos de G. Reyes (1990) y con los valores discursivo-pragmáticos de M. J. Serrano (2006) donde el énfasis principal está en el hecho de que el significado pragmático es el valor que adquiere un paradigma verbal en los usos efectivos. Es en ellos mismos donde el significado prototípico confluye con los demás significados del contexto asignando así a cada forma su valor completo (Reyes, 1990: 25). Las categorías verbales de tiempo, aspecto y modo se entrecruzan y posibilitan 'la manifestación del hablante’ y del contexto en la estructura lingüística originando los significados que llamaremos usos pragmático-discursivos.

\section{Criterio de la actualidad}

La relevancia del contexto para la interpretación de las formas verbales tiene sus raíces en el así llamado criterio de la actualidad que se empezó a formar ya en los años sesenta del siglo XX con É. Benveniste (1966) y H. Weinrich (1974). ${ }^{5}$ La conocida división de Benveniste entre historie y discours, dos tipos de enunciación que rigen sus propios paradigmas verbales, influye a Weinrich que a su vez habla de los tiempos del mundo narrado y del mundo comentado. El lingüista francés B. Pottier (1968) distingue entre el plano actual y el inactual mientras que el español V. Lamíquiz (1972) entre el nivel actual y el inactual: «La serie de formas temporales del nivel actual corresponde al discurso, la serie de formas temporales del nivel inactual corresponde a la historia.» (V. Lamíquiz, 1972: 60). Hemos de destacar que el criterio de la actualidad no es sintáctico sino discursivo ya que se realiza dentro de las restricciones contextuales: para la interpretación correcta del significado de una forma verbal determinada es importante tener en cuenta el contexto en que determinada forma aparece y la actitud del que habla.

En este artículo partimos de la sistematización que desarrolla, entre otros, el lingüista francés G. Luquet (2004) ${ }^{6}$ y que difiere esencialmente de la sistematización modal

\footnotetext{
${ }_{4}$ Por ejemplo el uso de la forma en -ra en el campo de indicativo (El gol que metiera John Zacharias fue el mejor gol de la liga), desaconsejada ya desde el año 1830 por V. Salvá en su Gramática, y por Andrés Bello en 1847 y después por muchos otros hasta la actualidad.

5 El concepto de 'actualité' aparece por primera vez en la gramática de Damourett y Pinchon a principios del siglo XX.

6 G. Luquet se basa en los conceptos teóricos de J. C. Chevalier, M. Launay in M. Molho, miembros del grupo de investigación MOLACHE (1980-1995), y en las divisiones ya mencionadas de É. Benveniste y H. Weinrich.
} 
más difundida en la lingüística española (indicativo, subjuntivo y, con características particulares, imperativo ${ }^{7}$ ). Creemos que la sistematización de Luquet no sólo logra aclarar algunos usos problemáticos que no se pueden explicar del todo dentro del sistema indicativo-subjuntivo, sino que también abre caminos importantes en cuanto a las posibilidades de interpretación de los paradigmas verbales en los textos poéticos como veremos más adelante.

El punto de partida es, primero, la división entre las formas simples que pertenecen a la morfología, y las formas compuestas, que pertenecen, según él, al campo de la sintaxis, por eso no las introduce a la sistematización. ${ }^{8} \mathrm{Al}$ mismo tiempo se destaca que las categorías básicas de las formas simples son tiempo, modo y persona (mientras que la $\mathrm{voz}$ y el aspecto pertenecen al campo de las formas compuestas), y que, además, no se pueden separar formalmente: el tiempo y el modo son morfológicamente indisociables. Ahora bien, según este punto de vista la principal división modal del verbo español consiste en distinguir entre dos grupos de formas verbales simples: formas actualizadoras y formas inactualizadoras, que a la vez originan dos modos: el modo actualizador y el inactualizador. Las primeras establecen la relación directa con el hablante, es decir, con su momento del habla o la representación del presente de experiencia (canto, canté, cantaré), mientras que las segundas se centran en la representación de un presente desconectado de cualquier experiencia del tiempo, es decir, en la representación de un presente ficticio, pura y simplemente imaginario, susceptible o no de coincidir con el presente de enunciación (cantaba, cantaría, cante, cantara, cantase) (Luquet, 2004: 66). Lo legítimo del ejemplo 'ayer, a las tres, llovía' prueba que un hablante sí es capaz de concebir 'otro' tipo de presente: de un presente abstracto, un presente inactualizado, a partir del cual se determinan, en su universo temporal, un pasado y un futuro igualmente inactualizados.

La diferencia principal de este enfoque con los anteriores es que cantaba no se incluye en el primer grupo y que canté se considera como forma actualizadora. ${ }^{9}$ No hay que confundir el tiempo que un paradigma verbal puede expresar en un enunciado y la representación del tiempo que está asociada a dicho paradigma en lengua. Dar por sentado que el imperfecto lleva consigo la representación del pasado (como se suele hacer) dificulta considerablemente la explicación de su perfecta compatibilidad con adverbios o construcciones verbales del tipo hoy, esta tarde, mañana, etc.

\footnotetext{
Con la excepción de Lamíquiz (1972), Alarcos Llorach (1994) y algunos otros.

8 El significado temporal básico de las formas compuestas se basa en que «el tiempo significado por la forma compuesta es anterior al tiempo del auxiliar» (A. Bello, §635). En casi cualquier estudio sobre el verbo español los paradigmas verbales compuestos con haber constituyen un área de investigación particular, tanto por su estructura como también por la necesidad del punto de referencia adicional para su correcta interpretación temporal. B. Comrie (1976) y P. Rivière (1981) señalan que las formas compuestas permiten dos modos de lectura, de aoristo y de perfecto lo cual dificulta aún más su sistematización; pero al mismo tiempo esto podría ser el argumento decisivo para analizar las formas simples y compuestas por separado.

9 El pretérito simple canté es inactual para É. Benveniste y H. Weinrich, mientras que V. Lamíquiz y B. Pottier lo consideran actual. Valenzuela Cervera (1978: 38), por otra parte, ofrece la sistematización que incluye al pretérito simple en los dos niveles, dependiendo del contexto: en el nivel actual de época pasada y en el nivel inactual de época presente.
} 
El subjuntivo viene a ser así un subconjunto de formas dotado de una verdadera identidad dentro del modo inactualizador que es a su vez una agrupación de los medios que el verbo pone a disposición de un hablante para desconectar totalmente de su universo de actualidad la representación de un acontecimiento. De ahí que actualizar o inactualizar consista en un proceso de objetivación del universo temporal del hablante: se asocia la representación de un acontecimiento a un universo formal directamente definido con relación al presente de experiencia o no.

Con la división entre las formas actualizadoras/inactualizadoras no se trata de negar el sistema indicativo/subjuntivo sino de ofrecer la explicación alternativa que se base en las propiedades conocidas incluyendo los argumentos ya establecidos dentro del sistema. Es un hecho que la explicación o el sistema que proporciona más respuestas que preguntas resulta más válido en el campo de investigación.

\section{Temporalización discursiva en la lírica}

«El poema nunca fue dicho por nadie a nadie, aunque, como enunciado ficticio, está siendo dicho, en un sentido, eternamente.»

B. Herrnstein Smith (1978)

Todo texto es un hecho lingüístico que un emisor pone en marcha con el fin de despertar ciertos efectos en un receptor: «el sólo uso de la palabra indica una comunidad (hablante, oyente, código, etc.), de lo contrario, estaríamos en el silencio» (Luján Atienza, 2005: 226). Por lo tanto, cuando un texto se 'pone en acción' en el proceso de la enunciación, el objeto de análisis ya no sólo es la estructura (TEXTUM) o el sistema sino, y sobre todo, el proceso y los mecanismos a través de los cuales el mismo sistema se actualiza y llega a formar el discurso (DISCURRERE). La constitución de la red temporal a través de los procesos comunicativos en un texto la llamaremos temporalización discursiva. En ella intervienen varios factores, no sólo los estrictamente temporales como veremos más adelante.

Si todo texto es comunicación ${ }^{10}$ también lo es un texto poético. Con cada acto de lectura de un poema se constituye un proceso dinámico de enunciación en que confluyen los textos poéticos y que llamaremos el discurso lírico. Los efectos específicos, que son la consecuencia de las circunstancias especiales en las que se construye e interpreta un texto poético, tiñen el proceso comunicativo en la lírica de matices poco frecuentes y un tanto insólitos, pero en el fondo siempre se trata de un acto comunicativo como en cualquier otra manifestación lingüística.

El texto poético origina el discurso lírico en un espacio y tiempo ficticios. En la poesía es por lo tanto fundamental que el acto de comunicación verbal no sea real sino ideal, ficticio o representado. Tampoco las funciones representativa, expresiva y co-

\footnotetext{
10 «Qualunque testo, orale o scritto, è un elemento di un atto di comunicazione - reale o potenziale, unico o plurimo - e si contradistingue per uno statuto comunicativo che dipende sia dalla particolarità interne del testo, sia dal carattere del suo funzionamento esterno. » (Levin, 1979: 426).
} 
nativa se ejercen realmente, sino de modo supuesto o ficticio: entre los interlocutores textuales.

El instrumento a través del cual entramos en la ficción discursiva, tanto narrativa como poética, es el 'pacto lírico' basado en el concepto de 'suspension of disbelief' del que hablaba ya el poeta y filósofo inglés S. T. Coleridge (1817). El lector acepta ciertas 'reglas de juego' a cambio del placer artístico. ${ }^{11}$ En un sentido es Alicia cruzando el espejo.

Cómo mínimo podemos destacar tres niveles de interlocutores en la lírica:

\section{[autor (poeta \{HABLANTE LÍRICO $\leftrightarrow$ RECEPTOR LÍRICO\} lector) lector]}

El centro de nuestro estudio es la relación interior: entre el hablante y el receptor líricos. El hablante lírico es una estrategia o función textual que aparece como el resultado de las relaciones entre las diferentes entidades que se comunican en un discurso lírico. No se trata del tradicional sujeto lírico, pero le puede corresponder (o no). El destinatario es el tú lírico, el tú ficticio, que no necesariamente está explícito en el texto.

Teniendo en cuenta la emotividad esencial de la lírica (frente a las relaciones lógicocausales en la épica y dramática) y el carácter ficticio de la temporalización discursiva, se puede concluir que la condición decisiva para la interpretación adecuada de las relaciones temporales en un discurso lírico va a ser la actitud directa o indirecta del hablante lírico hacia lo que dice. En otras palabras, la interpretación temporal de los paradigmas verbales en la lírica no es posible sin tener en cuenta la actitud del hablante. En la poesía la ubicación temporal se subordina a la actitud del hablante manifestando así en el nivel extralingüístico la relación inseparable entre la temporalidad y la modalidad: la modalidad se funde con la temporalidad. De ahí que el hablante lírico pueda establecer dos tipos de relación hacia lo dicho, cuyos centros respectivos son el presente actualizador (canto) y el 'presente' inactualizador (cantaba):

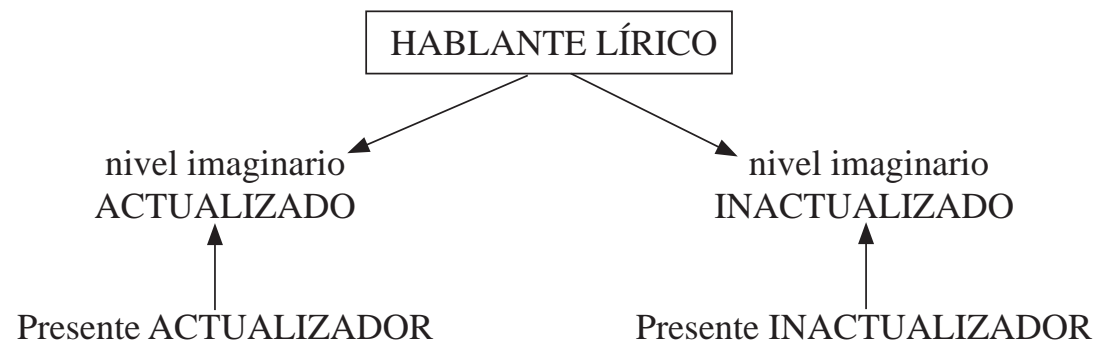

Esquema 1: Dos centros temporales del discurso lírico

\footnotetext{
${ }^{11}$ En el discurso lírico, por ejemplo, se espera que la forma no sea gratuita, que no sea sólo el adorno del contenido sino que dicta cierta forma de lectura. El sonido atribuye al significado o al revés: «Zven besede pomeni, pomen besede zveni». (B. A. Novak, 2009: 49).
} 
En los discursos poéticos no todo es presente, o bien no hay un solo presente (lo que suele sostenerse enfatizando la atemporalidad de la lírica) sino que se puede hablar de por lo menos dos centros temporales que establecen los dos niveles de la comunicación imaginaria. La temporalidad es inherente a la lírica. Aunque es verdad que en los discursos líricos prevalece el presente, esto no significa que otros paradigmas tengan el mismo valor atemporal. Cualquier hablante ubica a lo que dice y a sí mismo en una dimensión temporal: «Sin que haya una temporalidad objetiva expresada en la frase, hay siempre en el pensamiento del que habla una temporalidad, y ésta hará, según su valor, escoger la forma que más convenga a su significado.» (Alarcos Llorach, 1980: 30).

Las formas compuestas quedan sistematizadas en el siguiente esquema, pero es verdad que en los discursos líricos sí podemos hablar del predominio de los paradigmas verbales simples:

\begin{tabular}{|c|c|c|c|}
\hline \multicolumn{2}{|c|}{$\begin{array}{l}\text { SITUACIÓN COMUNICATIVA } \\
\text { NIVEL IMAGINARIO }\end{array}$} & & \\
\hline \multirow{2}{*}{$\begin{array}{l}\text { DISCURSO } \\
\text { LÍRICO }\end{array}$} & $\begin{array}{l}\text { PARADIGMAS } \\
\text { VERBALES } \\
\text { ACTUALIZADORES }\end{array}$ & $\begin{array}{l}\text { canto (ahora) } \\
\text { canté, cantaré }\end{array}$ & he cantado, (habré cantado) \\
\hline & $\begin{array}{l}\text { PARADIGMAS } \\
\text { VERBALES } \\
\text { INACTUALIZADORES }\end{array}$ & $\begin{array}{l}\text { cantaba }^{12} \text { (no-ahora) } \\
\text { cantaría, cante, } \\
\text { cantara, cantase }\end{array}$ & $\begin{array}{l}\text { había cantado, (habría cantado), } \\
\text { haya cantado, } \\
\text { hubiera cantado, hubiese cantado }\end{array}$ \\
\hline
\end{tabular}

Esquema 2: Paradigmas verbales y discurso lírico

La pragmática de la lírica abarca las relaciones entre los interlocutores, la relación del hablante hacia lo expresado (la modalidad) y los procedimientos de la temporalización y especialización discursiva a través de las cuales se constituye el discurso ficticio que condiciona el funcionamiento de las formas verbales.

El presente actualizador y el presente inactualizador son entonces dos centros principales de los discursos líricos y constituyen el eje de dos principales constelaciones temporales (preferimos el término constelación al programa temporal que es tal vez más apropiado para el discurso narrativo) que dependen de la relación directa o indirecta que establece el hablante lírico. La relación del hablante lírico frente a los interlocutores y a lo expresado se manifiesta en diferentes ‘figuras pragmáticas' de la lírica (tal y como

12 El poeta A. Machado veía el imperfecto como uno de los centrales paradigmas poéticos y lo consideraba como la forma con el mayor contenido temporal. El pretérito imperfecto español es sin duda una de las formas más abiertas y ambiguas ya que va desde el pasado al presente y se desprende hacia el futuro: su expresión inherente de una acción imperfectiva y durativa no deja de ubicarse de manera precisa en la línea temporal: siempre necesita puntos de referencia adicionales con ayuda de las cuales se determinan las relaciones entre las acciones expresadas. Será por eso que R. Barthes (1973) lo llama el ‘tiempo de la frustración’ o ‘de la acción frustrada’ que no acaba de cumplirse. 
las fija López Casanova, 1982) o ‘actitudes líricas’ (enunciación, apóstrofe, lenguaje de canción).

Las interrelaciones entre las (dos) constelaciones temporales (o témporo-modales) en el discurso lírico resultan en diferentes procedimientos de la temporalización discursiva. Se trata de una estrategia especial en la lírica con la que dispone el hablante lírico para segmentar y ordenar las sucesiones temporales en el marco discursivo, dictando así el ritmo de lectura. En la poesía las relaciones témporo-aspectuales y témporo-modales no se anulan sino que se realizan y funcionan en el nivel imaginario dentro de la realidad textual del proceso ficticio de la comunicación.

\section{Aplicación: Soledades, Eternidades, Historia del corazón ${ }^{13}$}

La temporalización discursiva en la lírica se ha analizado en las obras de tres poetas españoles cuyo gran tema es el tiempo y la temporalidad: Soledades de Antonio Machado, Eternidades de Juan Ramón Jiménez e Historia del corazón de Vicente Aleixandre. Se ha demostrado que los paradigmas verbales representan el elemento principal a la hora de la constitución de la red temporal poética pero que se organizan entre sí de manera distinta que en los textos narrativos. Se ha dicho más arriba que en la lírica, la expresión esencial del yo, es imprescindible partir de la actitud del hablante hacia lo dicho, de ahí que sean decisivas las relaciones témporo-modales entre los paradigmas verbales que funcionan en el nivel imaginario dentro de la comunicación ficticia. El análisis ha demostrado la existencia de dos constelaciones temporales principales en la lírica: actualizadora e inactualizadora donde el centro de la primera es el presente actualizador, canto, y de la segunda el inactualizador, cantaba. El paradigma central de cada texto se determina a base de tres factores: la frecuencia, la posición estratégica (al inicio o al final del verso y estrofa) y la posición sintáctica (parte principal o subordinada) en que se encuentra.

Es frecuente, sobre todo a partir de la lírica del siglo XX, que las dos constelaciones aparezcan juntas cubriéndose o superponiéndose. Estos procedimientos poéticos se llaman superposiciones temporales (el pasado y el presente se expresan simultáneamente, dentro de una misma oración) y yuxtaposiciones temporales (la sucesión directa de dos épocas que están alejadas en el sentido lógico-temporal). ${ }^{14} \mathrm{El}$ análisis de los textos poéticos de Machado, Jiménez y Aleixandre ha demostrado que el procedimiento principal para alcanzar el efecto de doble lectura temporal consiste en superponer o yuxtaponer el presente actualizado y el presente inactualizado: el simple cambio del paradigma establece una red temporal específica cuyo efecto es primordialmente modal (querer influir sobre el interlocutor), provocando los sentimientos diferentes en el lector. Se trata de una variante del estilo directo, pero en este caso la voz que se reproduce es la del poeta del otro momento. No se espera del lector que averigüe qué lectura es la adecuada: la fuerza expresiva se encuentra justo en la doble lectura.

\footnotetext{
13 En este apartado se resumen las principales conclusiones de la investigación que forma parte de la tesis doctoral sobre los paradigmas verbales en la poesía lírica (Pihler, 2009).

14 El marco teórico de estos procedimientos se lo debemos a Carlos Bousoño (1970).
} 
En los tres discursos líricos analizados prevalece la constelación actualizadora, con el porcentaje un poco menos alto de Historia del Corazón, lo que se debe probablemente a la especificad de su estructura textual que contiene algunos rasgos narrativos (lo que destaca también C.Bousoño, 1956: 93): hipotaxis, largas y complejas oraciones, la frecuencia más alta de las formas compuestas. Se demostró que la distribución del paradigma canté no sólo está relacionada sino que su relación con otros paradigmas es decisiva para la dimensión lírica o no-lírica del discurso. En los discursos líricos es más frecuente que la forma canté esté en la correlación con el presente actualizador (canto) que con el inactualizador (cantaba), de ahí que forme parte de la constelación actualizadora. Así ocurre, por ejemplo, en los discursos de Soledades y Eternidades. En Historia del corazón, al contrario, es frecuente la correlación de canté con cantaba, lo que puede servir de argumento para la supuesta narratividad del discurso. La dicha sistematización modal-temporal parece aún más adecuada si tenemos en cuenta que es imposible estudiar la lírica con los mismos puntos de partida que los textos narrativos o hacer conclusiones generales del tipo ‘en la lírica todo es presente’.

El predominio de uno u otro paradigma central en un texto poético influye en la organización de otros paradigmas y, además, en la expresión de los contenidos témporomodales determinados por la intención del hablante lírico y la constitución de figuras pragmáticas. A estos procedimientos básicos de la temporalización discursiva de la lírica se les unen las superposiciones y yuxtaposiciones temporales que se caracterizan por la apariencia de los dos paradigmas centrales en un mismo texto y, frecuentemente, por el desdoblamiento del hablante lírico.

El análisis de los tres discursos líricos ha mostrado, además, algunas estrategias lingüísticas más frecuentes con el fin de manipular el dinamismo temporal: la acumulación o de la elisión de los verbos con el fin de manipular el dinamismo textual; a través de la acumulación de las formas no personales a base del aspecto léxico; con el predominio de las perífrasis verbales con gerundio con el valor aspectual durativo-progresivo cuyo efecto es centrar la atención en el transcurso de la acción; con la correlación explícita entre la adverbializad temporal y los paradigmas verbales; con la alta frecuencia de complementos circunstanciales en relación con el aspecto y el tiempo y con las figuras retóricas relacionadas con el verbo y la adverbialidad temporal (anáfora, epífora, polisíndeton ...).

La lectura pragmático-lingüística de los textos poéticos ayuda a entender mejor las estructuras textuales internas abriendo, o bien, posibilitando así la interpretación adecuada de la red temporal discursiva, ya que ésta brota de las presuposiciones implícitas. El análisis, además, confirmó que la concepción filosófica de la temporalidad se refleja en la estructuración lingüística de cada discurso:

a) La 'palabra en el tiempo' de Machado refleja el flujo temporal con la intención principal de ir «contando y cantando sus personales historias de suerte tal que la 'melodía' no ocultase la 'historia'» (J. O. Jiménez, 1972: 22). El discurso de las Soledades no se rebela contra el tiempo sino que le dirige la palabra y se entrega al desasosiego con la 
conciencia de la propia fugacidad. La visión temporal de Soledades es la temporalidad individual, prevalecen las figuras pragmáticas de enunciación y apóstrofe:

A eso se unen también los recursos lingüísticos entre los cuales cabe mencionar: la red temporal transparente con los paradigmas verbales simples (en todo el discurso de Soledades hay un solo paradigma compuesto, he cantado), la correlación con los adverbios hoy, ayer, mañana, ya, todavía cuya consecuencia es centrarse en la experiencia interior de la fugacidad exterior por parte del hablante.

b) A través de todo el discurso de Eternidades se siente cierta adversidad contra el tiempo, tanto vital como lingüístico: la intención principal del hablante lírico es parar el tiempo en un eterno presente ya que «hay que imponerle la eternidad a la vida» (Jiménez, 1967: 981). La visión temporal de Eternidades es la temporalidad cíclica, tanto interior como exterior, cuyo centro es el 'yo':

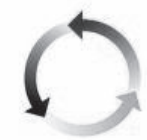

A todo lo anterior se le incorporan también los recursos lingüísticos, entre los cuales es la acumulación de los sintagmas nominales el más llamativo, sobre todo en los textos sin cualquier paradigma verbal. En cuanto a los paradigmas verbales predominan los aspectualmente imperfectivos y los copulativos que circulan en la mayoría de los casos alrededor del paradigma central de la constelación actualizadora acompañada de la adverbialidad sincrónica y absoluta. Eternidades centran la atención en el ahora del yo así que hay muy pocas superposiciones o yuxtaposiciones mientras que abundan varias figuras estilísticas de repetición (tanto en el nivel semántico como en el morfosintáctico).

c) El centro del discurso de Historia del corazón es la vida humana que es un largo y despacio ascender. Las figuras pragmáticas principales son apóstrofe y lenguaje de canción; Bousoño (1956: 93) llama a este tipo de lírica poesía de pensamiento hasta poesía realista. La temporalidad aleixandrina es el progreso común de varias temporalidades individuales que avanzan con ritmos distintos:



Lo más característico y lo más distintivo de Historia del corazón son extensos textos con largos versos libres en los que se acumulan diferentes paradigmas verbales (simples y compuestos) con un abanico de valores que se parecen a la distribución narrativa (la correlación de canté con cantaba). El hablante es a la vez externo e interno (yo testigo) y frecuentemente se desdobla en nosotros (tanto en el sentido de 
tú y yo, como de nosotros que abarca al lector) con efectos pragmáticos específicos. Predominan las relaciones aspectuales sobre los temporales con la especial atención en el lento progreso de la acción, señalado también con las figuras de polisíndeton, de hipérbaton y de la inversión que llama la atención sobre los elementos discursivos marginales.

\section{Conclusión}

A pesar de las diferencias mencionadas entre los tres discursos líricos analizados se han demostrado suficientes puntos en común en cuanto a la organización de los paradigmas verbales en la lírica a base de la cual se originan los efectos temporales específicos. El predominio de una u otra constelación y su intercambio discursivo se relacionan con el acercamiento y/o alejamiento del hablante lírico hacia lo que enuncia. La esencia de la dimensión temporal de la poesía viene a ser así la actualización de lo fugaz en lo durativo del ahora, de lo transitorio en los momentos eternos de la interioridad. Cada poema es atemporal pero con cualquier lectura se 'pone en acción' su temporalidad concreta que parte de un ahora a la vez fijo y a la vez movible y que se sigue (re)constituyendo con cada acto de lectura.

La temporalidad de la poesía se encuentra en el efecto que un discurso lírico despierta con toda la complejidad de recursos lingüísticos en el lector. Y parece que el efecto universal de la comunicación en la lírica no es ni presente ni atemporalidad sino la cotemporalidad, es decir, la existencia temporal simultánea: el texto poético funciona como un tiempo arquetípico que va volviéndose presente ya que «[...] el acto comunicativo en sí traza un arco que suspende el tiempo real y existe simultáneamente en el momento de anticipación que vive todo aquel que escribe y en el tiempo de retrospección que experimenta todo aquel que lee.» (Luján Atienza, 2005: 81).

Todo texto de cualquier género es un hecho de lengua y por lo tanto una rica fuente de información sobre el funcionamiento y la multitud de posibilidades de un sistema lingüístico. La tarea del investigador no se encuentra tanto en la ubicación y en la confirmación de ciertas estructuras de un texto sino sobre todo en averiguar qué funciones tiene y/o puede desempeñar y desde qué puntos de partida éstas se presentan relevantes para el análisis. El comentario lingüístico-pragmático de los textos revela por una parte la manera en la que el autor articuló la cadena lingüística, y, por otra, posibilita al autor y al lector que se concreticen en el discurso como múltiples participantes en la comunicación.

«La conquista de la poesía es como la del amor, que nunca sabremos si su secreto es nuestro, y contamos para siempre con la belleza y la fuerza de esa duda.»

Juan Ramón Jiménez, Estética y Ética estética 


\section{BIBLIOGRAFÍA}

Alarcos Llorach, E. (1994): Gramática de la lengua española. Madrid: Espasa Calpe.

Aleixandre, V. (1954/2001): Nacimiento último. Historia del corazón. Ed. de Irma Emiliozzi. Madrid: Edición Biblioteca nueva.

Bousoño, C. (1970): Teoría de la expresión poética. 2 tomos. Madrid: Gredos.

Comrie, B. (1976): Aspect. An Introduction to the Study of Verbal Aspect and Related Problems. Cambridge: Cambridge University Press.

Ducrot, O. (1984): El decir y lo dicho. Buenos Aires: Hachette.

Fuentes Rodríguez, C. (2000): Lingüística pragmática y análisis del discurso. Madrid: Arco/Libros.

Gadamer, H. G. (1996): «El lenguaje como medio de la experiencia hermenéutica». En: Verdad y método I. Salamanca: Ediciones Sígueme.

Herrnstein Smith, B. (1978): Al margen del discurso. La relación de la literatura con el lenguaje. Madrid: Visor.

Jiménez, J. R. (1967): Éstetica y ética estética. Madrid: Aguilar.

Jiménez, J. R. (1918/2007): Eternidades (1916-1917). Prólogo de Luis García Montero. Madrid: Visor Libros.

Lamíquiz, V. (1972): Morfosintaxis estructural del verbo español. Sevilla: Universidad de Sevilla.

Levin, J. I. (1973/1979). «La Poesia Lirica sotto il Profilo della Comunicazione». En: Carlo Prevignano (ed.) La Semiotica nei Paesi Slavi. Programmi, Problemi, Analisi. Milano: Feltrinelli. 426-442.

López-Casanova, A. (1994): El texto poético. Teoría y Metodología. Salamanca: Ediciones Colegio de España.

Luján Atienza, Á. L. (2005): Pragmática del discurso lírico. Madrid: Arco Libros.

Luquet, G. (2004): La teoría de los modos en la descripción del verbo español. Madrid: Arco/ libros.

Machado, A. (1907/2000): Soledades, Galerías. Otros Poemas. Ed. de Geoffrey Ribbans. Madrid: Cátedra.

Maestro, J. G. (1994): La expresión dialógica en el discurso lírico. Kassel: Universidad de Oviedo / Edition Reichenberger.

Olmo del Iturriarte, A.; Días de Castro, F. J. (ed.) (2007): Obras de Juan Ramón Jiménez. Eternidades. Visor Libros.

Pihler, B. (2009): Vloga glagolskih paradigem v poetičnih besedilih španskih pesnikov prve polovice dvajsetega stoletja: izražanje in interpretacija časovnosti. Disertacija. Ljubljana: Filozofska fakulteta.

Reyes, G. (1990): «Tiempo, modo, aspecto e intertextualidad». En: Revista española de lingüíastica. Año 20. Fasc. 1. Madrid: Gredos. 17-53. 
Rivière, C. (1980): «Tense, aspect and time location». En: Linguistics. 18. 105-135.

Serrano, M: J. (2006): Gramática del discurso. Madrid: Ediciones: Akal.

Wotjak, G. (1990): »El potencial comunicativo de los verbos«. En: Wotjak, G.; Veiga, A. (eds.): La descripción del verbo español. Verba. Anexo 32. Santiago de Compostela; Universidad de Santiago de Compostela, 265-285.

\section{GLAGOLSKE PARADIGME V LIRSKIH DISKURZIH MACHADA, JIMÉNEZA IN ALEIXANDRA: KRITERIJ AKTUALNOSTI}

Ključne besede: glagol, učasovljanje, aktualizirajoče in neaktualizirajoče oblike, lirski diskurz

Avtorica članka raziskuje distribucijo glagolskih paradigem v lirskih diskurzih treh španskih pesnikov, Antonia Machada, Juana Ramóna Jiméneza ter Vicenteja Aleixandra, z vidika pragmatičnega jezikoslovja. Izhaja iz predpostavke, da je sleherno besedilo, tudi pesniško, komunikativno naravnano, hkrati pa izpostavi potrebo po specifični sistematizaciji glagolskih paradigem v liriki, katere središče je lirski govorec znotraj fikcijskega sporazumevalnega procesa. Aplikacija kriterija aktualnosti, ki temelji na predpostavki morfološke neločljivosti glagolskega časa in naklona, se izkaže za zelo ustrezno predvsem v povezavi z bistveno idejno-racionalno in afektivno-emotivno dejanskostjo lirike (nasproti kavzalno-logičnim zaporedjem v dramatiki in epiki): časovne relacije med udeleženci komunikacije v lirskih diskurzih se namreč realizirajo po predhodni vzpostavitvi neposrednega oziroma posrednega odnosa govorca do sporočane vsebine. Oziroma: dejanske časovne vrednosti glagolskih paradigem v liriki so lahko ustrezno interpretirane šele, ko je jasen tudi posredni oziroma neposredni odnos govorca do povedanega. 